\title{
SUSTAINABLE DEVELOPMENT IN RESISTING ECOLOGICAL THREATS
}

\author{
Mohammed R. CHEHABEDDINE (i)*, Manuela TVARONAVIČIENE்(1) \\ Department of Business Technology and Entrepreneurship, Vilnius Gediminas Technical University, \\ Sauletekio al. 11, LT-10223, Vilnius, Lithuania
}

Received 25 February 2021; accepted 01 April 2021

\begin{abstract}
Purpose - this paper aims to ground an extended model of sustainable regional development, which would serve as an instrument to estimate and, ultimately, minimize the harmful impact of ecological threats on sustainable economic development.

Research methodology - Ecological Carrying Capacity (ECC) concept needs to be applied; chosen "COVID19" is as a valid sample of ecological pressure on regions to study its harmful impact on one of the ecological resource "GDP" for the vital group G20 countries that control 75\% of the world's GDP. Secondary data were collected from the Passport database's Macro model for evaluations and predictions.

Findings - GDP drop due to COVID19 in developed countries is higher than the developing countries of the G20 group, indicating the need to utilize the global sustainability EGB model instead of the SLB model.

Research limitations - considering one macro model indicator (GDP), which could be enhanced by including other indicators.

Practical implications - the obtained results promote a consistent reaction pattern of GDP growth with ecological threats in differently developed countries to devise economic policies on how to mitigate these threats' globally.

Originality/Value - previous studies mainly focused on identifying ecological threats, whereas our study studied how to measure these threats' harmful impact on countries' economies.
\end{abstract}

Keywords: ecological threats, sustainable development, ecological carrying capacity, global sustainability, COVID19, Real GDP, Macro model.

JEL Classification: O11, O19.

Conference topic: Business Processes: Development, Digitalization, Social Responsibility.

\section{Introduction}

Nowadays, Ecological threats are harming the development regionally due to its easy mobility through regions, harming economic development and, ultimately, sustainable development. It is necessary to understand how to avoid these ecological threats threatening regional development, so it is recommended to have a robust, sustainable development that can be a defence layer against these ecological threats to minimize their harms. Mitigating these threats requires predicting to find the necessary action against them, which is not usually an easy task due to the fast-changing environment. Conversely, enhancing our sustainable development through Global trade can have robust and sustainable development to resist ecological threats.

Since the ecological threats have an immediate impact on sustainable development, we aim to find a robust, sustainable development model that can resist these threats rather than each region to predict to mitigate these threats.

\section{Previous research}

Previous studies were mainly focused on studying sustainability models and indicators (Sakalauskas, 2010), identifying ecological threats and their impact, the interrelation of regional threats with sustainable development, and how ecological carrying capacity can promote regional sustainable development which is discussed below.

*E-mail: Mohamad.chehab-eddine@vilniustech.lt

(C) 2021 Authors. Published by Vilnius Gediminas Technical University. This is an open-access article distributed under the terms of the Creative Commons Attribution (http://creativecommons.org/licenses/by/4.0/) License, which permits unrestricted use, distribution, and reproduction in any medium, provided the original author and source are credited. 


\subsection{The interrelation between regional sustainable development and regional threats}

Sustainable development has been described in different ways, but there are three dimensions of sustainable development in practice: economic, environmental, and social. Sustainable development demands that environmental goals are integrated; the protection of natural resources and human health, which help to promote current and future growth; the interdependence between the pillars of sustainable development: the environment-economy (economic costs of preserving the environment), the economy-environment (pressure on environmental resources, pressure on environmental resources, environmental investment), environment - social (human welfare, health care through maintaining pure environment), social - environmental (ecological responsibility, consumption patterns), economy - social (providing jobs, good living, income), social - economy (labour quantity and quality) (Jovovic et al., 2017).

Attending one of these dimensions at the others' expense leads to unsustainable dynamics and outcomes (Khagram et al., 2003). The United Nations promoted the seventeen Sustainable Development Goals (SDGs) in 2015, showing that the Intersectional linkages among these goals are particularly revelatory of the forces structuring non-military stability. The revealed regional threats that are related to SGDs are originated from the below:

- Climate, Water, Sanitation, and Hygiene are linked to the new non-human environmental threats;

- Gender insecurities are linked to the old human sub-state threats affected by globalization;

- Health threats and micro enemies are linked to the upgraded non-human ecological threats.

\subsection{Ecological threats impact on sustainable development}

Ecological threats are amply analysed in the recent scientific literature. The following interconnected domains can be distinguished: water security (Cardoso et al., 2018; Monni et al., 2018; Moumen et al., 2019; Muniz et al., 2018); food security (Akhmadeev et al., 2019; Tireuov et al., 2018); energy security (El Iysaouy et al. 2019; Rezk et al., 2019; Tvaronavičienė \& Ślusarczyk, 2019) and health security (Besenyő \& Kármán, 2020).

The non-using of Green Energy sources emit toxic gases such as carbon dioxide and nitrogen monoxide, which are part of the pollution that impacts climate change and geoengineering and become ecological threats to our ecosystem. Ecological threats are one of the threats affecting sustainable development negatively.

These threats harm our environment and prone regions to the reduced disease resistance, which emergence of new infectious and non-communicable disease (such as pandemic COVID-19), issues related to anti-microbial resistance (AMR), issues related to water security, food security, and consequently, human security where climate change is the root cause of these issues. Therefore, these threats impose on ecosystems, such as (climate change, Geoengineering, micro-enemies, which affect our economic sustainability, which is a pillar of Sustainable development.

\subsection{The interrelation between Ecological Footprint with sustainability}

The Ecological Footprint is a country-level measurement of natural resources' human usage measured by contrasting the consumption footprint with the regional bio-capacity, where unsustainability is indicated by a negative balance (Global Footprint Network, n.d.) because it calculates the demand for and availability of nature by accounting.

On the demand side, The Ecological Footprint tests the ecological assets required by the community for the production of the natural resources it uses (including fibre and food products based on plants, fish goods, and livestock, forestry and other woodland products, urban infrastructure space) and for the absorption of waste, in particular carbon emissions. The usage of six categories of productive surface areas is monitored by Ecological Footprint: cropland, fishing lands, pasture fields, built-up land, woodland areas, and land demand for carbon.

On the supply side, the region or country's bio-capacity represents its ecological assets' productivity (includes cropland, timberland, fishing areas, and built-up land). These areas can also absorb most of the waste we generate, especially our carbon emissions, particularly if left unharvested (Global Footprint Network, n.d.). The Ecological Footprint will study the demand on and supply of nature of both developed and developing countries (Open Data Platform, n.d.).

\subsection{Using Ecological Carrying Capacity (ECC) for promoting regional sustainable development}

The Ecological Carrying Capacity (ECC) is the maximum of food supply on the capacity to sustain population growth "Population theory" by Wu and $\mathrm{Hu}$ (2020), used to represent the connection between human economic and social practices and the natural environment cantered on the link between "Carrier" or support object and a "bearing object" or pressure forces (Wu \& $\mathrm{Hu}, 2020$ ).

Hence, an ecosystem can provide the services and ecological conditions needed for human social structures' benign growth. The stronger the Ecological Carrying Capacity is, the greater the ecological environment's potential capacity to sustain human activities and social and economic development. It is composed of Ecological resilience (Environment, Water Resources, Land resources, Energy, mineral resources, self-recovery, and self-regulation) and 
Ecological pressures/stress (Economy, Society/Population, social activities, human activities, Economic activities, and Ecological threats (External factors) such as Pollution, climate change, Geoengineering, Pandemic COVID-19).

With the rapid growth of the economy, environmental challenges have become highly prevalent and threaten human society's sustainable development. Maintaining the sustainability of ecosystems and restricting human involvement are prerequisites for sustainable economic growth. Therefore, thoroughly knowing the regional ecological conditions and associated influential factors is critical for fostering sustainable regional growth. It is of considerable functional significance to research the ecological carrying capacity from a different view (Fang et al., 2017).

In recent years, the study on the ECC has concentrated on two aspects: the resource carrying capacity and environmental carrying capacity (Gong \& Jin, 2009; Wu \& Hu, 2020; Zhao et al., 2018), which include the single-factor environmental carrying capacity (e.g., water carrying capacity) and detailed environmental carrying capacity, but the primary study material is varied and involves various areas, sizes, times, and systems (Gong \& Jin, 2009; Wu \& Hu, 2020; Zhao et al., 2018).

As seen in Figure 1 below, the urban ecosystem is split into population subsystems, economic subsystems, and resources \& environmental subsystems; the partnership between the three subsystems is evaluated based on eco-economic theories; a theoretical structure for urban ecological carrying capacity is then developed. Due to the urban ecosystem being a complex area of varied feedback, a System Dynamics model, with three subsystems, analyses urban ecological carrying capacity. An open system dynamics model of the urban eco-economic system is set up, which is split into the population subsystem, economy subsystem, and resources and environment subsystem. The city's resources are split into external and internal resources, which are separately considered into urban ecological carrying capacity according to their various functions (Fang et al., 2017).

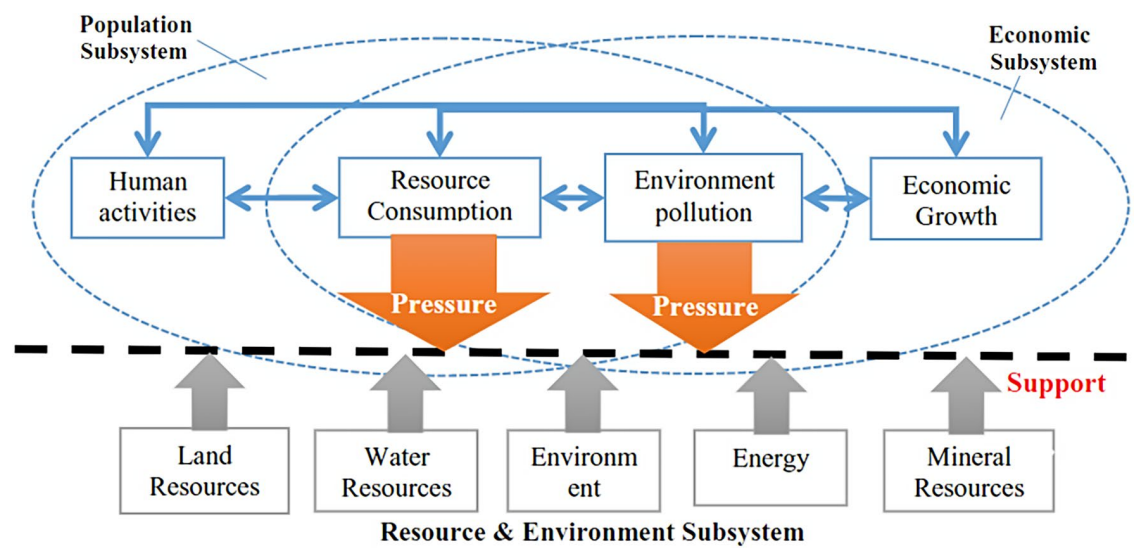

Figure 1. Framework of Urban Ecological Capacity Capability (source: Fang et al., 2017)

Population subsystem relates to the relationship of different factors attributable to people's living and behaviours in a community, consuming capital and impacting the climate. Economic subsystem relates to economies, such as companies and other economic entities, consume resources, and impact the environment. The resources and Environment subsystem was split into three parts: environmental resilience, artificial recovery, and the supply of resources (Fang et al., 2017).

In our research, ECC is composed of Ecological resilience represented by the environment carrying capacity, while Ecological pressures/stress represented by Ecological threats (External factors) such as pollution, climate change, Geoengineering, new infectious and non-communicable disease such as Pandemic COVID-19 (Wu et al., 2018).

It is required to study the impact of the ecological threats globally because these threats are borderless and can transfer globally, such as novel COVID-19 disease and Geoengineering where they affect the global economic sustainability and, most significantly the productive countries (developed countries, high population etc.) such as G20 countries, which control two-thirds of the world economy.

\section{Measuring sustainable development}

Sustainable development can be assessed with two overarching indicators:

- Measuring how well we all live using the Human Development Index (HDI) to track a nation's accomplishments in longevity, access to education, and revenue. Considering an HDI higher than 0.7 to be high human development.

- Measuring whether we live within the means of nature, using the Ecological Footprint. Considering an Ecological Footprint of less than 1.7 global hectares per person makes the resource demand globally replicable.

Note: The Ecological Footprint can be measured in global hectares per person or in "Number of Earths", representing how many planet Earths would take if everybody had this footprint. 


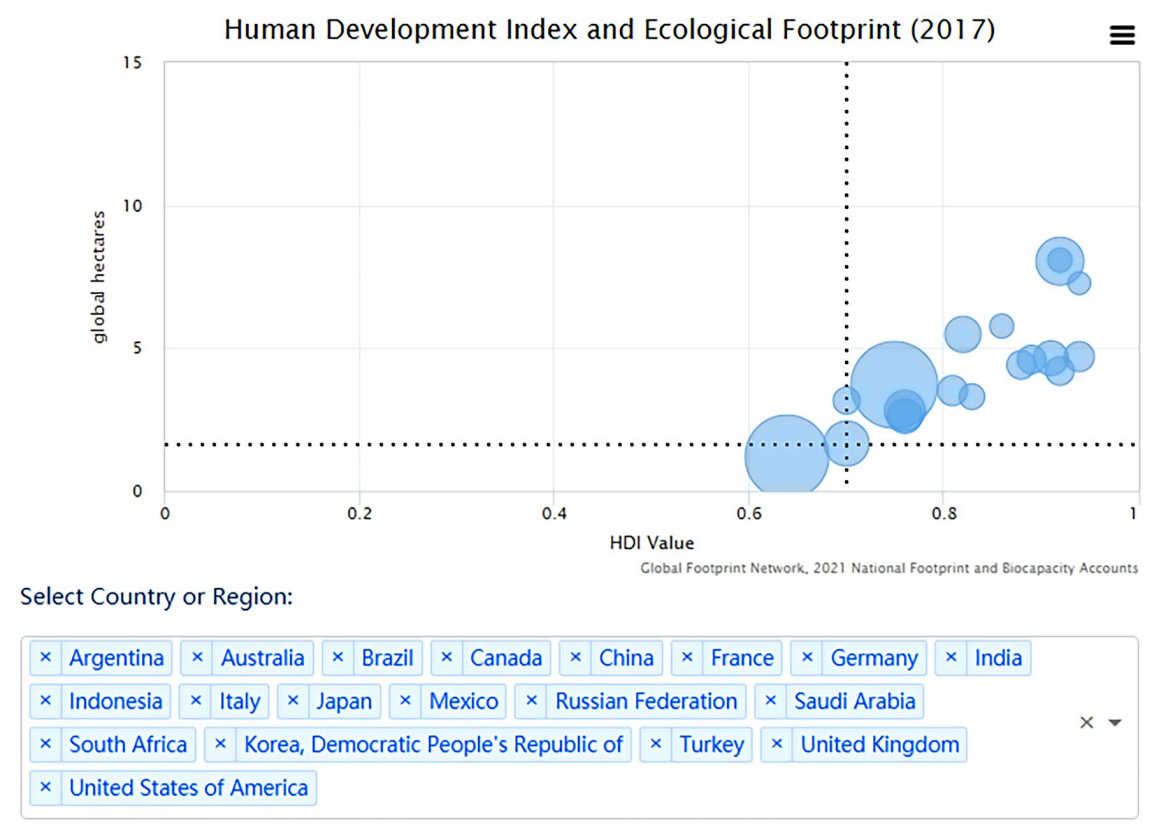

Figure 2. Human Development Index and Ecological Footprint for G20 countries (source: extracted by the authors)

Therefore, the conditions to be a Sustainable Development country:

- Human Development Index (HDI) > 0.7 (Human Development Reports, n.d.-a)

- Ecological Footprint $>1.7$, (Global Footprint Network, n.d.).

The upper right quadrant of the below Figure 2 shows the sustainable development countries of the G20 group.

\subsection{Sustainability perspectives}

Two models of Bio-economy (a reserve occurred if bio-capacity greater than Ecological Footprint):

- SLB (sufficient local bio-economy) model

It can be analogically extended to human society by not using more resources (the ecological footprint EF) than those available on its territory (bio-capacity) (Ecological debtor and creditor countries, 2006, comparing the... Download Scientific Diagram, n.d.) GFN (Global footprint network) model is a less strict version of the sufficient local bio-economy model. Adopting this approach would mean that all countries should estimate their so-called bio-capacity (if they unanimously adopt such term ultimately). Bio-capacity could be measured by specific hectares (gha pc), which would show regenerative potential.

Then ecological footprint hectares of a country could be compared with their bio-capacity hectares. The difference would indicate if ecological footprint exceeds bio-capacity or not. According to Syrovátka (2020), this could be a certain measure of sustainability. In case the bio-capacity of a particular country's hectare is higher than its ecological footprint, measured again in hectares, then it could be stated that the country has a sustainability reserve, which would justify its consumption mode. According to the available data, the Netherlands' ecological footprint is 5.9 hectares whereas, its bio-capacity is just 0.9 hectares, which shows a considerable deficit, which has to be immediately addressed by the full spectrum of respective national and international economic policy. An example of Canada reveals an entirely different picture. Adopting the same methodology provides the opposite result if we compare with Netherland: Canada's ecological footprint is just 8.0 hectares, while the ecological capacity is 15.2 hectares. It means that Canada is rather a sustainable country, and it can continue with a similar consumption mode in the future. Here we need to add that the provided above estimation is comparative, and like all scientific approaches, has its limitations. Therefore, the ultimate recommendation would be to foster circular behaviour irrespective of those calculations since the green gasses diffuse ultimately across the planet we live in it.

- The egalitarian global bio-economy (EGB) model

It is an alternate understanding of sustainability as focused on fair per citizen entitlements. Despite their birthplaces, suppose all citizens in the country have the same privilege to the planet's natural capital. Then it makes sense to measure the average global bio-capacity per capita ( $1.7 \mathrm{gha})$ and equate it with the respective national EFs per capita (Syrovátka, 2020). In this view, both Canada and the Netherlands are un-sustainable (with Canada possessing a more significant ecological deficit) (Syrovátka, 2020). 


\subsection{National self-sufficiency}

Each country has to care about its footprint. The countries with footprint indicators higher than their ecological capacity have to be indicated alas made known to the broad public. Both internal willingness and external pressure and support in some cases have to be employed for relevant national and international political implications were developed. Of course, the excessive footprint, in reality, is conditioned by a wide array of factors, not only consumption mode. We mentioned above already that all scientific approaches have their limitations. To return to the factors affecting footprints, they embrace such measurable indicators (besides consumption mode) as population density; productivity of land; the structure of agriculture; the structure of the economy, which differs by energy intensity; type of used energy mix, level of technological advancement; GDP growth; population structure and growth, etc.

Returning to concrete countries, from the sufficient local bio-economy view, a nation like the Netherlands will only operate by draining other areas ecologically (Wackernagel \& Silverstein, 2000, p. 393). However, from an economic viewpoint, this "can be used as part of a natural scenario where the exchange is mutually advantageous, rather than an indicator of non-sustainability" (Stiglitz et al., 2009). Notice also that the exporting nation can limit the export of bio-capacity (except carbon emissions) is considered harmful (Stiglitz et al., 2009).

\subsection{Global sustainability}

It is the viewpoint of a region consisting of self-sufficient local bio-economies, not inherently for the global sustainability paradigm, through extending the principle of carrying capacity on regions (Vanderheiden, 2008). It is one thing to suggest that the region does not surpass its habitats' re-generation and assimilation capacities. Another to require that this principle be met at a national (i.e., from the ecological point of view irrelevant). Trade provides for the export and import of bio-capacity; however, without it, countries' wealth will be constrained by their respective bio-capacities. The EF concept's dominant sustainability understanding provides for some trade-in bio-capacity, but domestic Consumption (i.e., production plus net imports) is essentially constrained by domestic bio-capacity. So for global sustainability, a bio-capacity-rich country can consume (either by import or by drawing on its bio-capacity) many bio-capacity-intensive products. Conversely, a bio-capacity-poor nation cannot, which happens even though the imports do not contribute to the overuse of bio-capacity in the exporting region. That is why contrasting national EFs with national bio-capacities brings anti-trade views.

\section{Methodology}

It is required to study the impact of the global risk scenario of ecological threats (dependent variable), such as COVID19, on the economy (independent variable) such as real GDP using the macro model for developed and developing countries. To check if there is a difference in the impact between them, that proves the need to utilize the global sustainability (EGB) model instead of the SLB model, ensure better sustainable development.

The steps of our methods are as follows:

- Selecting the contemporary ecological threat (such as COVID 19);

- Selecting a group of developed and developing countries (such as G20);

- Simulate the impact of the threat on these countries using (such as GDP retrieved from Passport database);

- Comparing the findings of both developed and developing countries (Drop-in GDP using Excel sheet);

- Conclude what could be the convenient, sustainable development model to resist ecological threats.

\subsection{Grounding/Scope}

G20 political group is chosen for our scope to ground our study because it represents around 80 percent of the world's GDP, one-third of the global population, and 75\% of all international trade. G20 representatives meet annually to discuss financial and socioeconomic issues. The scope was to study the impact of COVID19 as an ecological threat on the GDP as an indicator of economic development, starting from 2017 till 2027 simulated in the Passport database application.

\subsection{Data collection and analysis}

The secondary data collection will be collected from the Passport database to study the Macro Model's key indicators of developed and developing countries of the G20 group provided by Euro monitor International Company and powered by Clarivate Analytics. The data analysis will use a comparative analysis (Qualitative method) to measure the economy's development under global risk scenarios (Euromonitor International, n.d.).

The conditions to be in a Developed country (Kelley, 1991; Human Development Reports, n.d.-b; The World Bank, n.d.) are as follows:

- Human Development Index (HDI) > 0.8 (Human Development Reports, n.d.-a); 
- GDP (PPP > 22,000 \$);

- IMF status (International Monetary Fund, n.d.);

- OECD membership;

- World bank status.

Developed countries have high Economic growth (GDP per capita) and high Ecological Footprint because of increased Consumption. In contrast, developing countries have low economic growth (GDP per capita) and a low ecological footprint comparing to developed countries. In developed countries, the increase of economic growth reaches a certain point that the country becomes a green energy consumer using renewable energy where the Ecological Footprint will decrease, enhancing Environmental Sustainability and Economic Sustainability (Aye et al., 2017).

The above Figure 3 shows the findings of COVID-19 impact on different development countries categories of G20 presented graphically. Interpretation of the obtained results is provided below.

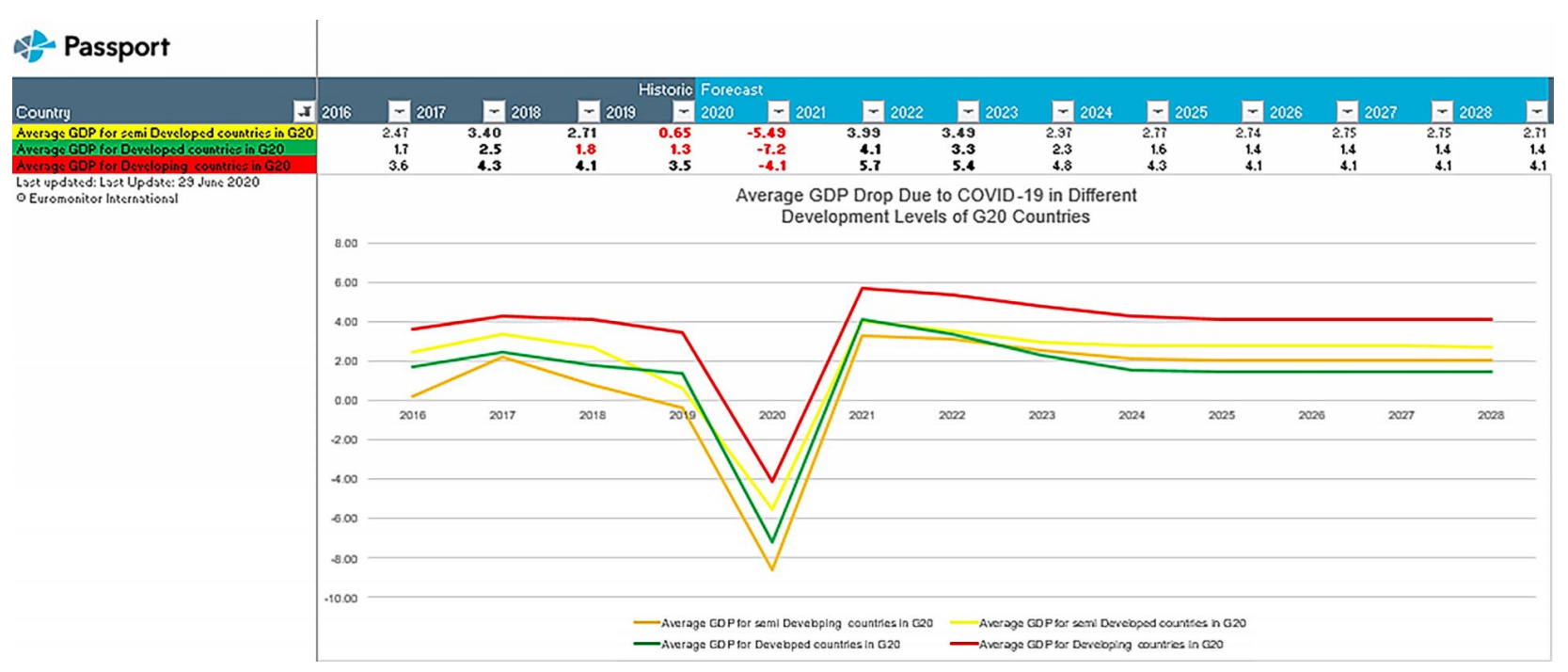

Figure 3. COVID-19 impact on different development countries categories of G20 (source: Euromonitor International, n.d., extracted by the authors)

\section{Results}

In our research, we study the impact of the ecological threats because these threats are borderless and can transition globally, e.g., novel COVID-19 disease, which affects the global economic sustainability and, the most significant impact appears to be on the most productive countries (developed countries, high population, etc.) such as G20 countries. Figure 3 provided above was obtained after getting the forecasted GDP values for developed and developing countries of G20 under the impact of COVID-19 retrieved from the Passport database.

Figure 3 shows the average GDP of developed countries (green colour curve) and developing countries (red colour curve) within the same group over ten years from 2017 till 2027.

We found that the difference in GDP drop due to the COVID-19 from 2019 till 2022 is higher in the developed countries comparing the developing countries, which is reflected clearly in Figure 3.

\section{Conclusions}

The analysis presented above allows us to reveal that the average GDP drop due to COVID-19 in developed countries of G20 is much higher than the developing countries in the same group, where the developed countries are highlighted in green colour, and the developing countries are highlighted in red colour. This difference in the GDP drop between them supports the need to utilize global sustainability (EGB model) instead of SLB since the enhancement of sustainable development using the EGB model for countries will build a defence layer to minimize these ecological threats impact.

The main research limitation is considering one macro model indicator (GDP) to evaluate the ecological threat impact on sustainable development. This research limitation could be neutralized by taking into account other relevant variables.

It is recommended to study the impact of the ecological threats using different indicators, either available or created depending on further studies aims. 


\section{Disclosure statement}

The authors declare that there is no conflict of interest regarding the publication of this article.

\section{References}

Akhmadeev, R., Redkin, A., Glubokova, N., Bykanova, O., Malakhova, L., \& Rogov, A. (2019). Agro-industrial cluster: Supporting the food security of the developing market economy. Entrepreneurship and Sustainability Issues, 7(2), 1149-1170. https://doi.org/10.9770/jesi.2019.7.2(25)

Aye, G. C., Edoja, P. E., \& Charfeddine, L. (2017). Effect of economic growth on $\mathrm{CO}_{2}$ emission in developing countries: Evidence from a dynamic panel threshold model. Cogent Economics \& Finance, 5(1), 1379239. https://doi.org/10.1080/23322039.2017.1379239

Besenyő, J., \& Kármán, M. (2020). Effects of COVID-19 pandemy on African health, political and economic strategy. Insights into Regional Development, 2(3), 630-644. https://doi.org/10.9770/ird.2020.2.3(2)

Cardoso, P. P., Swan, A., \& Mendes, R. (2018). Exploring the key issues and stakeholders associated with the application of rainwater systems within the Amazon Region. Entrepreneurship and Sustainability Issues, 5(4), 724-735. https://doi.org/10.9770/jesi.2018.5.4(2)

Ecological debtor and creditor countries, 2006, comparing the... Download Scientific Diagram. (n.d.). Retrieved January 17, 2021, from https://www.researchgate.net/figure/Ecological-debtor-and-creditor-countries-2006-comparing-the-ecological-footprint-of fig2_40755355

El Iysaouy, L., El Idrissi, N. E. A., Tvaronavičienè, M., Lahbabi, M., \& Oumnad, A. (2019). Towards energy efficiency: Case of Morocco. Insights into Regional Development, 1(3), 259-271. https://doi.org/10.9770/ird.2019.1.3(6)

Euromonitor International. (n.d.). Dashboard | Passport. Retrieved March 22, 2021, from https://www.portal.euromonitor.com/ portal/dashboard/index\#/key-indicators

Fang, W., An, H., Li, H., Gao, X., \& Sun, X. (2017). Urban economy development and ecological carrying capacity: Taking Beijing City as the case. Energy Procedia, 105, 3493-3498. https://doi.org/10.1016/j.egypro.2017.03.801

Global Footprint Network. (n.d.). Ecological Footprint. Retrieved May 29, 2020, from https:/www.footprintnetwork.org/our-work/ ecological-footprint/

Gong, L., \& Jin, C. (2009). Fuzzy comprehensive evaluation for carrying capacity of regional water resources. Water Resources Management, 23(12), 2505-2513. https://doi.org/10.1007/s11269-008-9393-y

Human Development Reports. (n.d.-a). Human Development Data Center. Retrieved March 22, 2021, from http://hdr.undp.org/ en/data\#

Human Development Reports. (n.d.-b). Human Development Index (HDI). Retrieved January 17, 2021, from http://hdr.undp.org/ en/content/human-development-index-hdi

International Monetary Fund. (n.d.). IMF Data. Retrieved March 22, 2021, from https://www.imf.org/en/Data

Jovovic, R., Draskovic, M., Delibasic, M., \& Jovovic, M. (2017). The concept of sustainable regional development-institutional aspects, policies and prospects. Journal of International Studies, 10(1), 255-266. https://doi.org/10.14254/2071-8330.2017/10-1/18

Kelley, A. C. (1991). The human development index: "handle with care". Population \& Development Review, 17(2), $315-324$. https://doi.org/10.2307/1973733

Khagram, S., Clark, W., \& Firas Raad, D. (2003). From the environment and human security to sustainable security and development. Journal of Human Development, 4(2), 289-313. https://doi.org/10.1080/1464988032000087604

Monni, S., Iorio, M., \& Realini, A. (2018). Water as freedom in the Brazilian Amazon. Entrepreneurship and Sustainability Issues, 5(4), 812-826. https://doi.org/10.9770/jesi.2018.5.4(8)

Moumen, Z., El Idrissi, N. E. A., \& Tvaronavičienė, M. (2019). Water security and sustainable development. Insights into Regional Development, 1(4), 301-317. https://doi.org/10.9770/ird.2019.1.4(2)

Muniz, J., de Melo, M. da G. G., Liberato, M. A. R., Wahnfried, I., \& Vieira, G. (2018). Towards sustainability: Allowance rights for using water resources in Amazonas State of Brazil. Entrepreneurship and Sustainability Issues, 5(4), 761-771. https://doi.org/10.9770/jesi.2018.5.4(5)

Open Data Platform. (n.d.). Retrieved March 22, 2021, from https://opendataplatform.org/

Rezk, M. R. A., Radwan, A., Salem, N. M., Sakr, M. M., \& Tvaronavičienė, M. (2019). Foresight for sustainable energy policy in Egypt: results from a Delphi survey. Insights into Regional Development, 1(4), 357-369. https://doi.org/10.9770/ird.2019.1.4(6)

Sakalauskas, L. (2010). Tvarumo modeliai ir indikatoriai. Technological and Economic Development of Economy, 16(4), $567-577$. https://doi.org/10.3846/tede.2010.35

Stiglitz, J. E., Sen, A., \& Fitoussi, J.-P. (2009). Report by the commission on the measurement of economic performance and social progress. https://www.insee.fr/en/statistiques/fichier/2662494/stiglitz-rapport-anglais.pdf

Syrovátka, M. (2020). On sustainability interpretations of the Ecological Footprint. Ecological Economics, 169, 106543. https://doi.org/10.1016/j.ecolecon.2019.106543

Tireuov, K., Mizanbekova, S., Kalykova, B., \& Nurmanbekova, G. (2018). Towards food security and sustainable development through enhancing efficiency of grain industry. Entrepreneurship and Sustainability Issues, 6(1), 446-455. https://doi.org/10.9770/jesi.2018.6.1(27)

The World Bank. (n.d.). DataBank. World Development Indicators. Retrieved January 17, 2021, from https://databank.worldbank. org/Human-development-index/id/363d401b 
Tvaronavičienè, M., \& Ślusarczyk, B. (2019). Energy transformation towards sustainability. Elsevier. https://doi.org/10.1016/C2018-0-02510-4

Vanderheiden, S. (2008). Two Conceptions of Sustainability. Political Studies, 56(2), 435-455. https://doi.org/10.1111/j.1467-9248.2007.00691.x

Wackernagel, M., \& Silverstein, J. (2000). Big things first: Focusing on the scale imperative with the ecological footprint. Ecological Economics, 32, 391-394. https://doi.org/10.1016/S0921-8009(99)00161-5

Wu, H., Yu, Y., Li, S., \& Huang, K. (2018). An empirical study of the assessment of green development in Beijing, China: Considering resource depletion, environmental damage and ecological benefits simultaneously. Sustainability, 10(3), 719. https://doi.org/10.3390/su10030719

Wu, X., \& Hu, F. (2020). Analysis of ecological carrying capacity using a fuzzy comprehensive evaluation method. Ecological Indicators, 113. https://doi.org/10.1016/j.ecolind.2020.106243

Zhao, C., Wang, C., Yan, Y., Shan, P., Li, J., \& Chen, J. (2018). Ecological security patterns assessment of Liao River Basin. Sustainability, 10(7), 2401. https://doi.org/10.3390/su10072401 